\title{
Small Spoken Corpus and Oral English Classroom
}

\author{
Hui $L i^{1, a}$ \\ ${ }^{1}$ Faculty of Foreign Languages, Huaiyin Institute of Technology, Huai'an 223003, China \\ aalanlee9@126.com
}

Keywords: register; spoken corpus; oral English

\begin{abstract}
This paper shows how small self-made corpus of spoken language will be applied in oral English classroom in China. It has been illustrated that both students and teachers had lacked register awareness in oral English teaching and learning from a linguistic aspect. Students' weaknesses in oral English drillings will be shown in the self-made corpus and instructions about spoken register will be given to them.
\end{abstract}

\section{Introduction}

The use of corpus has been applied in language learning and teaching for years. It has become the centre of linguistics. Especially the spoken corpus "amasses large quantities of texts and processes it to make it accessible for study" [1]. This paper focuses on two critical issues:

What problems do Chinese students confront in their oral English class?

How do we apply self-made spoken corpus in oral English teaching in Classroom?

In this paper, definition of register will be addressed from the systemic-functional perspective, followed by the problems of register awareness of Chinese students in oral English class. The advantages of Self-made spoken corpus will then be introduced. Later how to apply the corpus in oral English teaching and learning will be explained. Finally I will come to a conclusion for future prospects.

\section{Register research}

The definition of register is not easy to define. In the Longman Dictionary of Language Teaching and Applied Linguistics it refers to "a speech variety used by a particular group of people, usually sharing the same occupation or interests"[2]. A particular register often bares the distinctive features by using words or phrases in a particular way, or by special grammatical constructions from other registers.

\section{Register and genre}

However, register is often intertwined with genre, a similar term. Genre is defined as "a type of discourse that occurs in a particular setting, that has distinctive and recognizable patterns and norms of organization and structure, and that has particular and distinctive communicative functions"[2]. That is to say, it is closely related to contexts or social situations, for example, business reports, news broadcasts, speeches etc.

According to Lee, the two terms are the most confusing, and are often used interchangeably, mainly because they overlap to some degree[3]. One difference between the two is that genre tends to be associated more with the organization of culture and social purposes and is tied more closely to considerations of ideology and power, whereas register is connected with organization of situation or immediate context theoretically based on the tradition of systemic-functional grammar.

Much of the register research deals with the language features and their context of utterance. For example, the levels of formality, interpersonal aspects of meaning, spoken and written differences. McCarthy noted that the most notable research was conducted by Halliday. He also added what we should teach about spoken language on the layers of structural features, interactional feature, generic feature, contextual constraints[4]. 


\section{Register awareness of EFL learners}

In China, oral English is an important part in college English teaching. According to the "College English Curriculum Requirement"[5], the objective of College English is to develop students' ability to use English in a well-rounded way, especially in listening and speaking, so that in their future studies and careers as well as social interactions they will be able to communicate effectively. As a result, the oral English teaching situation from the perspectives of teacher and students' quality, awareness, teaching environment, ways of evaluation and propose some solutions has been analyzed. Being an instructor, it is indispensable for a teacher to adopt appropriate methods of teaching, for instance, integrated teaching, second language acquisition teaching, mate-language education, small class and online learning. No doubt those studies are beneficial to the promotion of oral language teaching and learning.

In fact, most language learners cannot understand the distinctive features of written and spoken register from the learners' corpora in China. That is to say, they speak written languages and write spoken languages[6]. Professor Gui Shichun in China addresses that it is a common phenomenon that foreign language learners lack the awareness of register[7]. In addition, language teacher often makes no sense of spoken register. Corpora of spoken languages play a critical role in oral English teaching. To use spoken corpus in classroom can provide students authentic materials and enhance the awareness of spoken register.

\section{Corpus-based approach}

Computer makes itself a special role currently in the language study which provides a new perspective to the language description. The retrieval of data from corpora can present objective, authentic evidence for the reliability of research. The history of corpus linguistics tells us "corpora have opened up a large range of research lines in the study and teaching of language"[8]. Two types of comparison lie at the heart of studies using corpora: "one is to compare native language and interlanguage; the other is to compare different types of interlanguage (the language of different sub-corpora) with each other"[9]. A learner corpus is assembled for the study on the characteristics of English as a foreign language or a second language. This kind of corpus presents evidence of an interlanguage.

However spoken language is much more difficult to analyze because it is subjected to dynamic characteristics with real-time constraints. Halliday notes that spoken language is a foundation for grammatical theory "the spoken language corpus is a primary resource for enabling us to theorize about the lexico-grammatical stratum in language, and thereby about language as a whole[10]. Kennedy prospects that studies of spoken interaction and the basis of cohesion in spoken texts are likely to continue to be central in corpus-based descriptive studies[11].

\section{Self-made spoken corpus used in classroom}

Although spoken corpus is more difficult and expensive to design and compile, it is indeed beneficial to language research. As a guide in classroom, teacher may face to many difficulties in collecting spoken materials in class, transcribing the audio language to texts, even tagging the raw texts. The recorded materials hail from the real classroom of oral English. The teachers could keep track with classroom activities for the whole semester. The activities are recorded with desired quality including monologues, dialogues, presentations and discussions. These are the authentic materials spoken by our own students so that teacher could possibly examine the spoken language features of them. By such a doing, register features could be explored from lexical, structural and discoursal level and instructions will be given.

\section{Lexical level}

In daily conversations we can find a deluge of general features of lexicons. The extracted language from self-made corpus can help us to find and explain the spoken features of EFL students in 
classroom. Some lexicon forms like smallwords, fixed chunks, and collocations can contribute to the fluency of their oral English. Smallwords have been identified to play a key role in indicating fluency, because these words make contributions to coherence[12]. The most frequently used smallwords are well, right, all right, okay, you know, you see, I know, I see, oh, ah, I think, I mean, like, sort of /kind of etc. Fixed chunks include the fixed expressions and idiomatic expressions. McCarthy underlines that chunks are not created anew each time we speak, and they are automatic expressions which enables effortless accuracy[13]. Teachers should put the weight on the interactive chunks which can influence the learners' register choices.

\section{Structural level}

In the face-to-face communication, some structural choices will influence the interpersonal exchanges. McCarthy presents us some criteria for choosing some certain grammatical structures in spoken discourse. Tense, voice, aspect, position of clause elements, clause complexes are the important concerns in spoken language[14]. In their studies, they describe some spoken grammar which can create appropriate interpersonal meanings. For example, progressive forms like wanting, liking, having to function as a strategy that minimizes imposition and threat to face. Passive voice are actually used in academic papers rather than spoken language. This has been proved in previous research with the exception of get-passive.

\section{Discoursal level}

On the discoursal level, I will mainly emphasize cohesion. The concept of cohesion was introduced by Halliday and Hasan in their book Cohesion in English in 1976. It refers to "relations of meaning that exist within a text and that define it as a text"'[15]. The concept is thus a semantic one, de facto cohesion is explicitly realized in the superficial structure of the text via linguistic features (such as grammatical and lexical elements), just like all components of the semantic system. Grammatical cohesion includes devices such as reference, ellipsis, substitution, conjunction, while lexical cohesion includes reiteration and collocation.

Conjunction is one of the five types of cohesive relation, which is actually on the borderline of grammatical and lexical cohesion: mainly grammatical but with a lexical component in it. Conjunction refers to larger inventory of connectors which link clauses in discourse. In spoken discourse some conjunctions like so, then, though and anyway. To avoid some misuse and overuse of this kind of conjunctions, we can use some examples to explain that kind of phenomenon.

\section{Conclusion}

With the help of spoken corpus, teachers can to some extent examine the students' spoken language features and give timely instructions to utter the appropriate spoken register. I just discuss several aspects in the scope of lexicon level, structural level, and discoursal level which is a segment of a whole. The examination of learners' spoken language is an urgent issue in language teaching and learning. With more spoken corpora generated we can have a very close look at the EFL learner's register awareness and therefore some linguistic research will give a help to our learners and pedagogical technology.

\section{Acknowledgements}

This work was financially supported by the Youth Foundation Program of Huaiyin Institute of Technology (HGC1224).

\section{References}

[1] M.A.K. Halliday, in: Advances in Corpus Linguistics, edited by K. Aijmer and B. Altenberg, World Publishing Corporation, Beijing (2009). 
[2] J.C. Richards, R. Schmidt, H. Kendrick and Y. Kim: Longman Dictionary of Language Teaching and Applied Linguistics( $3^{\text {rd }}$. eds)(Foreign language teaching research press, Beijing 2005)

[3] D. Lee, in: Teaching and Learning by Doing Corpus Analysis, edited by B. Kettemann and G. Marko, World Publishing Corporation, Beijing(2009).

[4] M. McCarthy: Spoken Language and Applied Linguistics (World Publishing Corporation, Beijing 2006).

[5] Information on http://www.chinanews.com/edu/kong/news/2007/09-26/1036802.shtml

[6] Q. F. Wen and Y. R. Ding: A Corpus-based Analysis of Frequency Adverbs used by Chinese English Majors. Modern Foreign Language Vol. 27 (2004), pp.150-156.

[7] S. C. Gui: A Corpus-based Analysis of the Register of English Linguistics (Foreign Language Teaching and Research Press, Beijing 2009)

[8] J. Sinclair: Corpus, Concordance, Collocation (Oxford University Press, Oxford 1991)

[9] K. Aijmer, in: Computer Learner Corpora, Second Language Acquisition and Foreign Language Teaching, edited by S. Granger, J. Hung and S. Petch-Tyson, John Benjamins Publishing Company, Amsterdam/Philadelphia(2002).

[10] M.A.K. Halliday, in: Advances in Corpus Linguistics edited by K. Aijmer and B. Altenberg, World Publishing Corporation, Beijing (2009).

[11] G. Kennedy: An Introduction to Corpus Linguistics. ( Addison Wesley Longman Limited, London 1998).

[12] A. Hasselgren, in: Computer Learner Corpora, Second Language Acquisition and Foreign Language Teaching, edited by S. Granger, J. Hung, and S. Petch-Tyson, John Benjamins Publishing Company, Amsterdam/Philadelphia (2002).

[13] M. McCarthy, in: Explorations in Corpus Linguistics, edited by M. McCarthy, Cambridge University Press, Cambridge, UK ( 2006).

[14] M. McCarthy and R. Carter, in: Explorations in Corpus Linguistics, edited by M. McCarthy, Cambridge University Press, Cambridge, UK ( 2006).

[15] M. A. K. Halliday and R. Hasan: Cohesion in English (Longman, London1976). 